Eur. J. Clin. Chem. Clin. Biochem.

Vol. 32, 1994, pp. 329-336

(C) 1994 Walter de Gruyter \& Co.

Berlin $\cdot$ New York

\title{
Impaired Immunoglobulin G Fc Fragment Function in Diabetics is Caused by a Mechanism Different from Glycation
}

\author{
By Roswitha Dolhofer-Bliesener, Brigitte Lechner and K. D. Gerbitz
}

Institut für Klinische Chemie und Institut für Diabetesforschung, Städtisches Krankenhaus München-Schwabing, Akademisches Lehrkrankenhaus der Universität München, München, Germany

(Received January 14, 1994)

Summary: Glycation and fluorescence at $440 \mathrm{~nm}$ (excitation at $370 \mathrm{~nm}$ ) were found to be increased in immunoglobulin $\mathrm{G}$ (IgG) from diabetics, strongly indicating the presence of IgG-linked advanced glycosylation end products. In contrast, levels of IgG-linked advanced glycosylation end products were low or undetectable in both normal and diabetic subjects when an advanced glycosylation end products specific antibody was employed for immunological determination of advanced glycosylation end products. Furthermore, no correlation exists between IgG glycation, fluorescence and immunoreactivity. In diabetics, the Fc fragment of IgG showed decreased protein A binding and decreased fixation of complement. This impairment of biological activity was not correlated with the immunologically determined level of advanced glycosylation end products, whereas IgG-linked fluorescence was inversely related to complement fixing activity. These results indicate that mechanisms different from glycation or browning are responsible for changes in the functional properties of IgG.

\section{Introduction}

In glycation, glucose reacts with free amino groups of proteins to form labile Schiff bases, which subsequently undergo Amadori rearrangement to stable ketoamines. Formation of Amadori products is well established for a number of proteins and has been found to be increased in diabetes (for a review see l. c. (1)). The Amadori product undergoes very slowly a series of still unknown rearrangement reactions to form yellow-brown, fluorescent and cross-linking substänces, called advanced glycosylation end products. These browning products are thought to accumulate on proteins and to play an important role in the development of diabetic late complications (for a review see 1.c. (2)).

Our recent studies indicate that glycation of immunoglobulin $\mathrm{G}(\mathrm{IgG})$ in vitro leads to IgG fluorescence and polymerization (3), concomitant with marked changes in functional properties of the Fc fragment $(4,5)$ ). In view of the possible pathophysiological relevance of these findings, we examined the biological activity of the $\mathrm{Fc}$ fragment of IgG from normal and diabetic subjects. Fur- thermore, the possible involvement of IgG-linked advanced glycosylation end products was investigated with the aid of an advanced glycosylation end products specific enzyme-linked immunosorbent assay (ELISA). Evidence is presented, indicating that the Fc fragment of IgG from diabetics is functionally impaired, and that this impairment is unrelated to glycation or formation of advanced glycosylation end products.

\section{Materials and Methods}

Materials

Bovine serum albumin, sheep blood and amboceptor 6000 were from Behringwerke, Marburg/Lahn, Germany. The Glyco-Gel B Test Kit was from Pierce, Oud-Beijerland, The Netherlands; the enzyme immunoassay for determination of human IgG subclasses from The Binding Site, Birmingham, U. K.; DEAE-cellulose (DE52) from Whatman BioSystems, Maidstone, U.K.; keyhole limpet haemocyanin from Calbiochem, Bad Soden, Germany; peroxidaselinked sheep anti-rabbit IgG from Boehringer, Mannheim, Germany. All other chemicals were from Sigma, Deisenhofen, Germany, or from E. Merck, Darmstadt, Germany. 


\section{Methods}

Serum was obtained from 43 normal healthy persons (ranging between 21 and 58 years of age) and from 43 diabetic patients (1775 years old) attending the outpatient service for diabetic care of the hospital München-Schwabing, an Academic hospital of the University of Munich. Patients were included irrespective of type of treatment. Informed consent was obtained from all subjects before venepuncture.

Immunoglobulin $\mathrm{G}$ from human serum was purified by precipitation with $\left(\mathrm{NH}_{4}\right)_{2} \mathrm{SO}_{4}$ and chromatography on DEAE-cellulose, as previously described (4). The purification procedure yielded highly purified IgG preparations as revealed by polyacrylamide gel electrophoresis, sodium dodecyl sulphate polyacrylamide gel electrophoresis and immunoelectrophoresis.

IgG was quantified in a Beckman Array protein system or by measurement of absorbance at $280 \mathrm{~nm}$. Human IgG subclasses 1 , 3 and 4 were determined by enzyme immunoassay according to the supplier's instructions. The level of glycated IgG in percentage of total IgG was measured by affinity chromatography (6) using the Glyco-Gel B test kit. IgG $(2 \mathrm{mg})$ was applied to the top of an aminophenylboronic acid column and further processed according to the supplier's instructions. Absorbance of bound and unbound fractions was determined at $280 \mathrm{~nm}$ in a Shimadzu UV-260 spectrophotometer.

Advanced glycosylation end products were estimated by measurement of IgG absorbance at $350 \mathrm{~nm}(7,8)$ at a protein concentration of $1 \mathrm{~g} / \mathrm{l}$ in a Shimadzu UV-260 spectrophotometer. In addition, IgG-linked fluorescence at $440 \mathrm{~nm}$ upon excitation at $370 \mathrm{~nm}(7$, 8) was determined at an IgG concentration of $0.5 \mathrm{~g} / \mathrm{l}$ in an AmincoBowman spectrofluorometer. Absorbance at $350 \mathrm{~nm}$ and relative fluorescence were expressed relative to the absorbance at $280 \mathrm{~nm}$.

Advanced glycosylation end product proteins (derived from human albumin, human IgG, human transferrin, bovine albumin and bovine globulin) were prepared in vitro by incubating $43.3 \mu \mathrm{mol} / \mathrm{l}$ of the respective protein for 34 days at $37^{\circ} \mathrm{C}$ with $55.5 \mathrm{mmol} / \mathrm{l}$ glucose in $0.05 \mathrm{~mol} / 1$ 2-amino-2-methyl-propanol-(1) buffer, $\mathrm{pH} 9.5$, containing $1.2 \mathrm{mmol} / 1 \mathrm{MgSO}_{4}, 5.4 \mathrm{mmol} / \mathrm{l} \mathrm{KCl}, 26.2 \mathrm{mmol} / \mathrm{l}$ $\mathrm{NaHCO}_{3}, 116 \mathrm{mmol} / 1 \mathrm{NaCl}, 6 \mathrm{mmol} / \mathrm{l} \mathrm{NaN}{ }_{3}$ and $10 \mathrm{mg} / \mathrm{l}$ gentamicin, followed by dialysis against $154 \mathrm{mmol} / 1 \mathrm{NaCl}$. Poly- $L$-lysine $\left(M_{r} 15000\right.$ to 30000$)(5 \mathrm{~g} / \mathrm{l})$ was incubated at $37^{\circ} \mathrm{C}$ in the presence of $1.67 \mathrm{~mol} / \mathrm{l}$ glucose for 18 days in 2-amino-2-methyl-propanol(1) buffer.

Advanced glycosylation end products were detected immunochemically essentially as described by Nakayama et al. $(9,10)$. Briefly, keyhole limpet haemocyanin $(20 \mathrm{~g} / \mathrm{l})$ was incubated under sterile conditions in the absence and presence of $2.2 \mathrm{~mol} / \mathrm{l}$ glucose at $37^{\circ} \mathrm{C}$ in $0.4 \mathrm{~mol} / 1 \mathrm{Na}$-phosphate buffer, $\mathrm{pH} 7.5$, for twelve weeks. After extensive dialysis against $154 \mathrm{mmol} / \mathrm{l} \mathrm{NaCl}$, rabbits were immunized with $1 \mathrm{mg}$ advanced glycated and non-glycated keyhole limpet haemocyanin, respectively, emulsified in incomplete Freund's adjuvant, followed by 7 booster injections at 2-week intervals.

Antisera titres were determined in a non-competitive ELISA. Wells of microtitre plates (Nunc immunoplates) were coated overnight at $4^{\circ} \mathrm{C}$ with $0.1 \mathrm{ml}$ of advanced glycosylation end products protein, $0.5 \mathrm{mg} / \mathrm{l}$ in $0.1 \mathrm{~mol} / 1$ carbonate buffer, $\mathrm{pH}$ 9.6. The wells were washed with $154 \mathrm{mmol} / \mathrm{l} \mathrm{NaCl}$ containing $0.5 \mathrm{ml} / 1$ Tween 20 , then blocked with $5 \mathrm{~g} / \mathrm{l}$ bovine serum albumin in phosphate-buffered saline, $\mathrm{pH}$ 7.4. Rabbit antisera dilutions $(0.1 \mathrm{ml})$ were added to the wells and incubated for two hours at room temperature. Thereafter, wells were washed again and developed with a peroxidase-conjugated anti-rabbit IgG from sheep, using $o$-phenylenediamine as substrate. Absorbance at $450 \mathrm{~nm}$ was read on a Microplate reader MR 6000 (Dynatech).

IgG-linked advanced glycosylation end products were assayed in a competitive ELISA. Microtitre plates were coated by adding 0.1 $\mathrm{ml}$ human advanced glycosylation end products $\mathrm{IgG}, 0.5 \mathrm{mg} / \mathrm{l}$, in
$0.1 \mathrm{~mol} / \mathrm{l}$ carbonate buffer, $\mathrm{pH}$ 9:6. After incubation overnight, wells were washed and blocked with $0.2 \mathrm{ml} 5 \mathrm{~g} / \mathrm{l}$ bovine serum albumin in phosphate buffered saline, $\mathrm{pH} 7.4$. Thereafter, $0.05 \mathrm{ml}$ of samples (IgG, $2 \mathrm{~g} / \mathrm{l})$ and $0.05 \mathrm{ml}$ of $1: 1000$ diluted rabbit antiserum were added to the wells. Plates were incubated for 2 hours at room temperature and overnight at $4^{\circ} \mathrm{C}$, and further processed as described for the non-competitive assay. A calibration curve was prepared from serial $1: 2$ dilutions of human advanced glycosylation end products IgG, corresponding to IgG protein concentrations of 200 to $3.1 \mathrm{mg} / \mathrm{l}$. Relative fluorescence of the respective dilutions ranged from 2 to 0.03 . Immunoreactivity of samples was read from the calibration curve and was expressed as advanced glycosylation end products units, one advanced glycosylation end products unit corresponding to the amount of antibody-reactive material found in standard advanced glycosylation end products IgG at a protein concentration of $1 \mathrm{mg} / \mathrm{l}$ ( 1 advanced glycosylation end products unit $=1 \mathrm{mg} / 1$ advanced glycosylation end products IgG protein). The calibration curve was linear from 6 to 100 advanced glycosylation end products units. Determinations were run in triplicate. The intra-assay coefficient of variation was $7.1 \%$ $(\bar{x}=118$ advanced glycosylation end products units, $n=16)$ while the inter-assay coefficient of variation was $1.0 .8 \%(\bar{x}=23$ advanced glycosylation end products units, $n=31$ ) and $12 \%$ $(\bar{x}=7.4$ advanced glycosylation end products units, $n=28)$.

Protein A reactivity and complement $\left(C^{\prime}\right)$ fixation were determined as described previously (5). Statistical evaluation was performed according to the instructions of Sachs (11). Statistical significance was calculated by Student's t-test for unpaired data. Results are given as mean values $\pm \mathrm{SD}$.

\section{Results}

Immunoglobulin $G$ was prepared from sera from 43 non-diabetic apparently healthy subjects, as well as from 43 diabetic patients displaying mean $\mathrm{HbA}_{1 \mathrm{c}}$ levels of $5 \%$ (range $3.9 \%-5.6 \%$ ) and $9 \%$ (range $4.6 \%-13.7 \%$ ), respectively. The IgG concentration was found to be essentially the same in normal and diabetic sera (10.6 $\pm 1.9 \mathrm{~g} / \mathrm{l}$ and $10.7 \pm 2.3 \mathrm{~g} / \mathrm{l})$. Furthermore, IgG subclasses 1,3 and 4 were determined in the preparations. No difference in the content of IgG subclasses was observed.

Levels of glycated IgG were found to be markedly increased in diabetic patients as revealed by affinity chromatography on boronate gel. Expressed as a percentage of total IgG (in analogy with $\mathrm{HbA}_{1 \mathrm{c}}$ ), glycation amounted to $4.1 \pm 0.87 \%$ (range $2.2 \%-5.7 \%, \mathrm{n}=43$ ) and $10.3 \pm 4.5 \%$ (range $2.9 \%-21.1 \%, n=43, p<0.0005$ ) in normal and diabetic subjects, respectively. A clear correlation $(r=0.705)$ was demonstrable between $\mathrm{HbA}_{1 \mathrm{c}}$ and glycated IgG in diabetics (data not shown).

The possible occurrence of protein-bound brown and/or fluorescent chromophores, indicating the formation of advanced glycosylation end products $(7,8)$, was investigated by measurement of absorbance at $350 \mathrm{~nm}$ and of fluorescence at $440 \mathrm{~nm}$ upon excitation at $370 \mathrm{~nm}$. As revealed by determination of absorbance at $350 \mathrm{~nm}$, IgG browning was essentially the same in normal and diabetic subjects, amounting to $3.6 \pm 1.56$ and $3.7 \pm 1.98$ $\left(10^{3} \times\right.$ A $\left.350 \mathrm{~nm} / \mathrm{A} 280 \mathrm{~nm}, \ddot{\mathrm{n}}=15\right)$. In contrast, $\mathrm{IgG}$ 


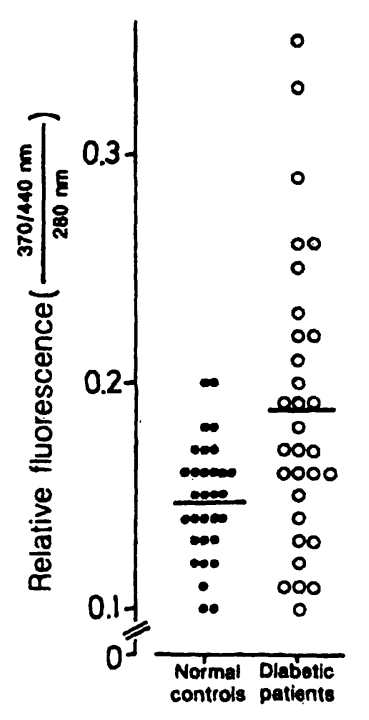

Fig. 1 IgG-linked fluorescence in normal $(\bullet)$ and diabetic (0) subjects.

In purified IgG $(0.5 \mathrm{~g} / \mathrm{l})$, fluorescence at $440 \mathrm{~nm}$ upon excitation at $370 \mathrm{~nm}$ was measured and related to absorbance at $280 \mathrm{~nm}$. Mean values are indicated by the horizontal bars.

fluorescence was markedly elevated in diabetic patients, as shown in figure 1. Mean values of the ratio of fluorescence to absorbance at $280 \mathrm{~nm}$ were 0.148 (SD $=0.026, \mathrm{n}=31)$ in controls and $0.19(\mathrm{SD}=0.063$, $\mathrm{n}=31, \mathrm{p}<0.0025)$ in diabetics. Absorbance at $350 \mathrm{~nm}$ and the relative fluorescence were independent of the age of the patients. In controls and diabetics no interrelationship was found between glycated IgG and ab-

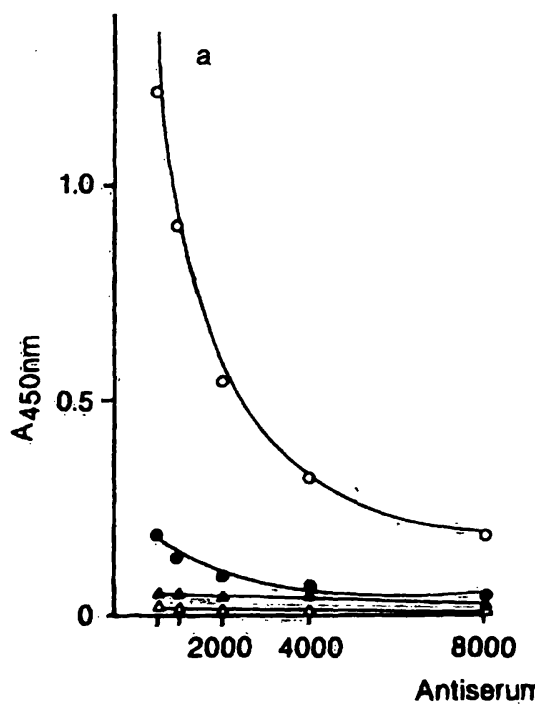

Fig. 2 Dilution curves for antisera to advanced glycated keyhole limpet haemocyanin and to keyhole limpet haemocyanin.

Wells of microtitre plates were coated with native and in vitro glycated human albumin (a), human IgG (b), human transferrin (c), bovine albumin (d) and bovine globulin (e). Immunoreactivity was determined in a non-competitive ELISA as described in Materials and Methods.

Reaction of:

(•) native protein with advanced glycated keyhole limpet haemocyanin antiserum sorbance at $350 \mathrm{~nm}$, between glycated $\operatorname{IgG}$ and relative fluorescence, or between absorbance at $350 \mathrm{~nm}$ and relative fluorescence.

Since browning products are not specifically assayed by measurement of fluorescence, antibodies against advanced glycated keyhole limpet haemocyanin were prepared essentially according to 1.c. (9). The properties and specificity of the antibody were very similar to those described by Nakayama et al. (9) for anti-advanced glycated keyhole limpet haemocyanin antibody, and by others, using advanced glycosylation end products derived from bovine serum albumin or from ribonuclease as antigen $(12,13)$. A non-competitive ELISA showed that antiserum from a rabbit immunized with advanced glycated keyhole limpet haemocyanin reacted with advanced glycosylation end products derived from human IgG, albumin, transferrin and from bovine albumin and globulin (fig. 2). A weak reaction was also observed with unmodified proteins, indicating the presence of low amounts of advanced glycosylation end products structures in native proteins, generated from in vivo glycated proteins or during storage (14). Neither advanced glycosylation end products proteins nor native proteins gave a reaction with antisera from rabbits immunized with keyhole limpet haemocyanin incubated in the absence of glucose.

To determine the specificity of the anti-advanced glycosylation end products antibody, unmodified proteins, ad-

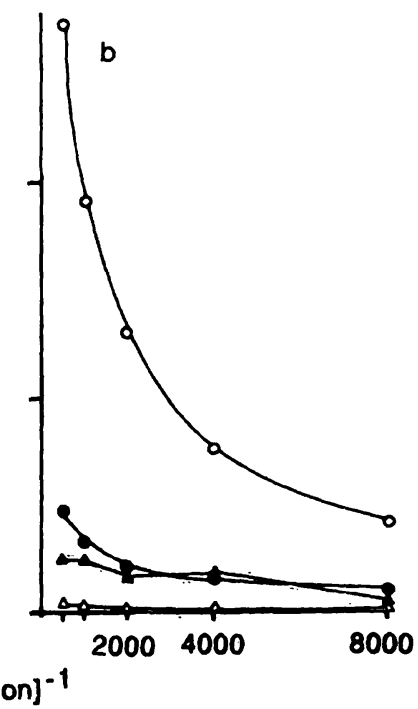

(O) advanced glycosylation end products protein with advanced glycated keyhole limpet haemocyanin antiserum

(A) native protein with keyhole limpet haemocyanin antiserum

$(\Delta)$ advanced glycosylation end products protein with keyhole limpet haemocyanin antiserum 

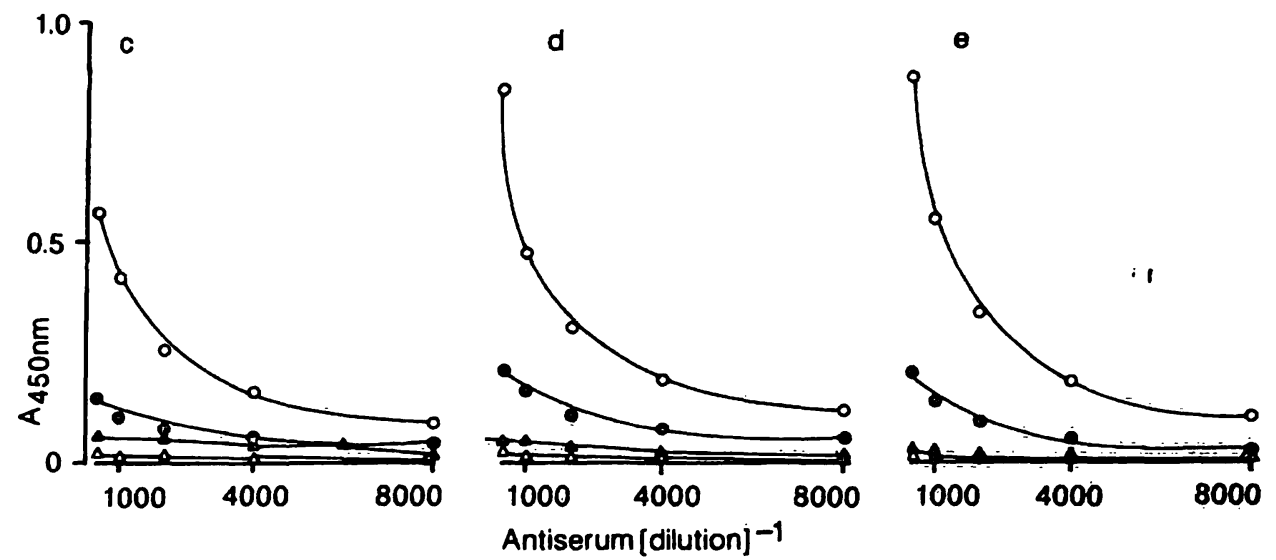

Fig. 2 (continued)

Reaction of:

$(\bullet)$ native protein with advanced glycated keyhole limpet haemocyanin advanced antiserum

(O) advanced glycosylation end products protein with advanced glycated keyhole limpet haemocyanin antiserum

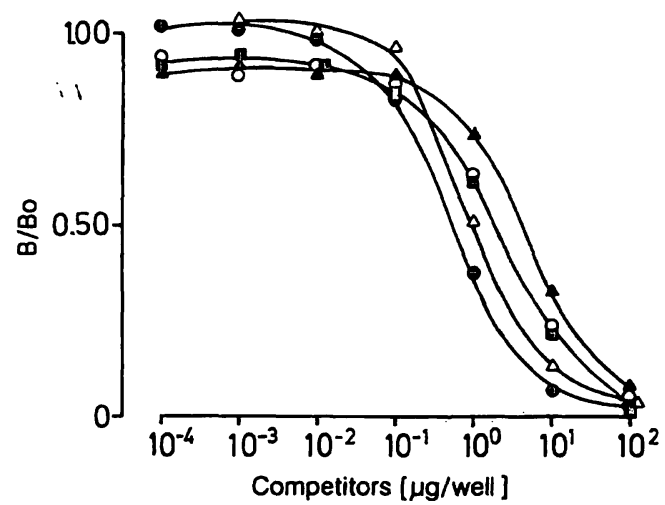

Fig. 3 ELISA competitive inhibition curves for advanced glycosylation end products proteins.

Microtitre plates were coated with $0.5 \mathrm{mg} / \mathrm{l}$ advanced glycosylation end products human albumin. Competitors were added to the wells at the concentrations given on the abscissa and further processed in a competitive ELISA as described in Materials and Methods. Results were expressed as $B / B_{0}$, where $B$ is sample absorbance and $B_{0}$ is absorbance in the absence of competitor (total absorbance). Advanced glycosylation end products protein derived from

(o) human albumin

(O) human IgG

(A) human transferrin

$(\Delta)$ bovine albumin

(a) bovine globulin

Nearly identical results were obtained when microtitre plates were coated with advanced glycosylation end products IgG:

vanced glycosylation end products proteins and poly- $L$ lysine were tested in a competitive assay. Figure 3 shows ELISA competition curves for anti-advanced glycated keyhole limpet haemocyanin-antiserum. It can be seen that advanced glycosylation end products derived from human and bovine albumin showed the greatest inhibition, while the weakest inhibition was shown by advanced glycosylation end products derived from human transferrin. The inhibition curves of different advanced glycosylation end products proteins were parallel to each other.
$(\Delta)$ native protein with keyhole limpet haemocyanin antiserum $(\Delta)$ advanced glycosylation end products protein with keyhole limpet haemocyanin antiserum

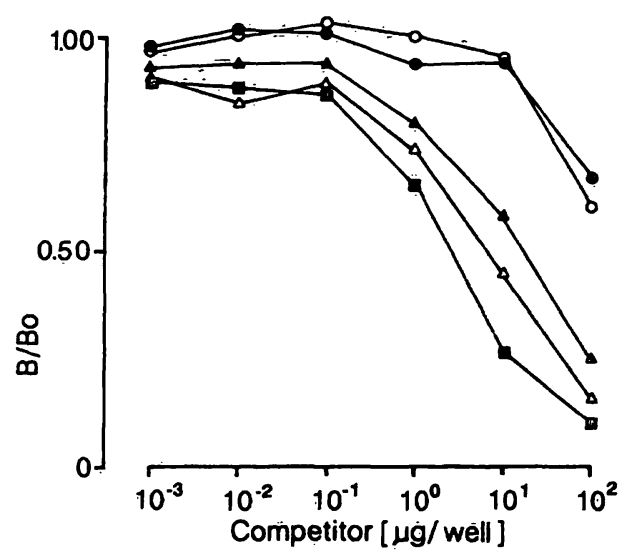

Fig. 4 Increase in immunoreactivity as a function of incubation time.

Microtitre plates were coated with $0.5 \mathrm{mg} / \mathrm{l}$ advanced glycosylation end products derived from human albumin. Native human IgG (•) and IgG incubated with glucose for $3(0), 9(\Delta), 18(\Delta)$ and 34 (E) days, respectively, was added to the wells at the concentrations given on the abscissa and further processed in a competitive ELISA as described in Materials and Methods. Nearly identical results were obtained when plates were coated with advanced glycosylation end products derived from IgG.

Immunological reactivity of proteins glycated in vitro increased with the time of incubation with glucose (fig. 4). Furthermore, poly- $L$-lysine incubated with glucose showed marked inhibition in competitive ELISA, while no competition for antibody binding was discernible from the starting material or from poly- $L$-lysine incubated without glucose (fig. 5). In order to establish whether Schiff bases or Amadori products are recognized by the antibody, advanced glycosylation end products proteins were reduced with $\mathrm{NaBH}_{4}$. After reduction, the immunoreactivity of advanced glycosylation end products proteins remained esșentially unchanged (data not shown), indicating that glycation products, 


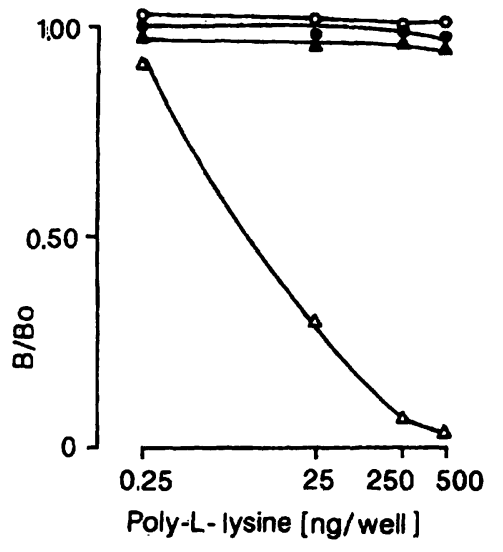

Fig. 5 ELISA competitive inhibition curve for advanced glycosylation end products derived from poly- $L$-lysine.

Microtitre plates were coated with $0.5 \mathrm{mg} / \mathrm{l}$ advanced glycosylation end products derived from human albumin. The competitor was poly-L-lysine: starting material in the absence $(\bullet)$ and presence $(0)$ of glucose; after 18 days of incubation in the absence $(\Delta)$ and presence $(\Delta)$ of glucose. Nearly identical results were obtained when wells were coated with advanced glycosylation end products derived from $\mathrm{IgG}$.

Schiff bases and Amadori products, were not the antigenic epitopes.

The relationship between fluorescence and immunoreactivity during in vitro incubation is shown in figure 6. A time-dependent increase in fluorescence concomitant with an increase in immunoreactivity was observed in albumin samples incubated with glucose. It is noteworthy that an approximate twofold increase in fluorescence occurred in samples incubated without glucose, while no change in immunoreactivity was detected.

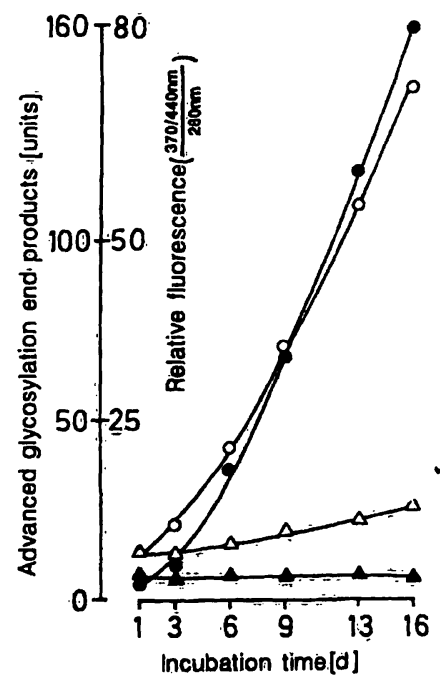

Fig. 6 Increase in immunoreactivity and relative fluorescence during glucose incubation.

Human albumin was incubated in the absence (triangles) and presence (circles) of glucose. At the times indicated on the abscissa, relative fluorescence (open symbols) and immunological reactivity (closed symbols) were determined as described in Materials and Methods.

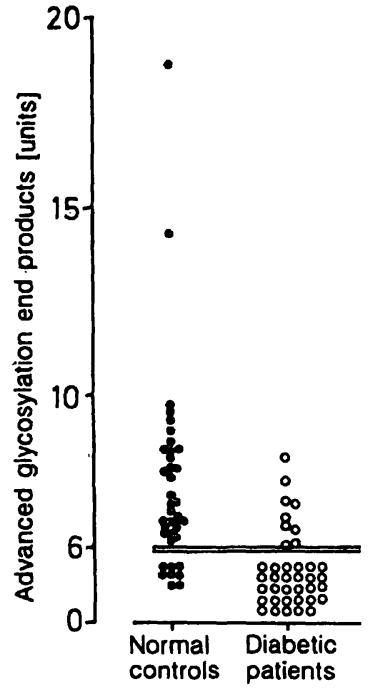

Fig. 7 Levels of immunologically determined advanced glycosylation end products in IgG from normal controls ( $(0)$ and diabetic patients (O).

The horizontal lines indicate the detection limit of the ELISA.

In order to determine whether fluorescence of IgG from normal and diabetic subjects is related to IgG immunoreactivity, the protein-bound advanced glycosylation end products content of purified IgG was examined in a competitive ELISA. Unexpectedly, IgG preparations contained only small amounts, if any, of immunologically reactive material (fig. 7), which was 3 to 5 times lower than expected from the measurement of IgGlinked fluorescence.

Furthermore, IgG-linked advanced glycosylation end products levels were found to be higher in normal controls than in diabetics. In 8 out of 38 normal subjects, and in 29 out of 38 diabetics, advanced glycosylation end products values were lower than the detection limit ( 6 advanced glycosylation end products units). Immunologically determined levels of IgG-linked advanced glycosylation end products were not correlated with glycated IgG or with IgG-linked fluorescence (fig. 8). In this connection, it is noteworthy that no immunologically reactive material could be detected in albumin purified from 5 normal and 5 diabetic sera, although these albumins showed high fluorescence at $440 \mathrm{~nm}$ upon excitation at $370 \mathrm{~nm}$ (data not shown).

In order to investigate possible functional changes of diabetic IgG, binding of protein A and complement fixation, both occurring within the Fc fragment of IgG, were measured. In diabetics, a statistically significant decrease in protein A reactivity was observed; $53 \mu \mathrm{g}$ $(\mathrm{SD}=16.9, \mathrm{n}=40)$ and $45 \mu \mathrm{g}(\mathrm{SD}=13.7, \mathrm{n}=41)$ of IgG were bound by $12.5 \mu \mathrm{g}$ of protein $\mathrm{A}$ in normal and diabetic subjects, respectively $(p<0.0125)$. Finally, a complement fixation test revealed a decrease in complement fixing activity of $\mathrm{IgG}$ from diabetics. In normal 


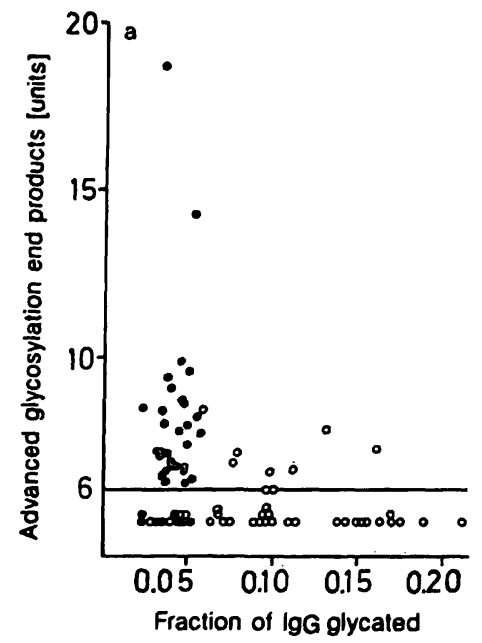

Fig. 8 Lack of correlation between immunologically determined advanced glycosylation end products and glycated IgG (a) and rel-

controls, complement fixation amounted to $70 \pm 21 \%$ $(n=43)$, whereas in diabetics the mean value was found to be $59 \pm 27 \%(n=42, p<0.025)$; in five out of 42 diabetics $C^{\prime}$-fixation was almost abolished. This decrease in $C^{\prime}$-fixation was apparently independent of the age of the patients, the IgG subclass content of the sample, the IgG concentration in serum, the level of blood glucose, cholesterol, triacylglycerols, $\mathrm{HbA}_{1 \mathrm{c}}$, glycated IgG, the absorbance at $350 \mathrm{~nm}$, or the amount of immunologically determined advanced glycosylation end products. However, a relationship between $\mathrm{C}^{\prime}$-fixation and IgG fluorescence was observed in diabetic patients. It is evident from figure 9 that fluorescence and $C^{\prime}$-fixation are inversely correlated. Using IgG from diabetics, it was found that $C^{\prime}$-fixation values $<40 \%$, between $40 \%$ and

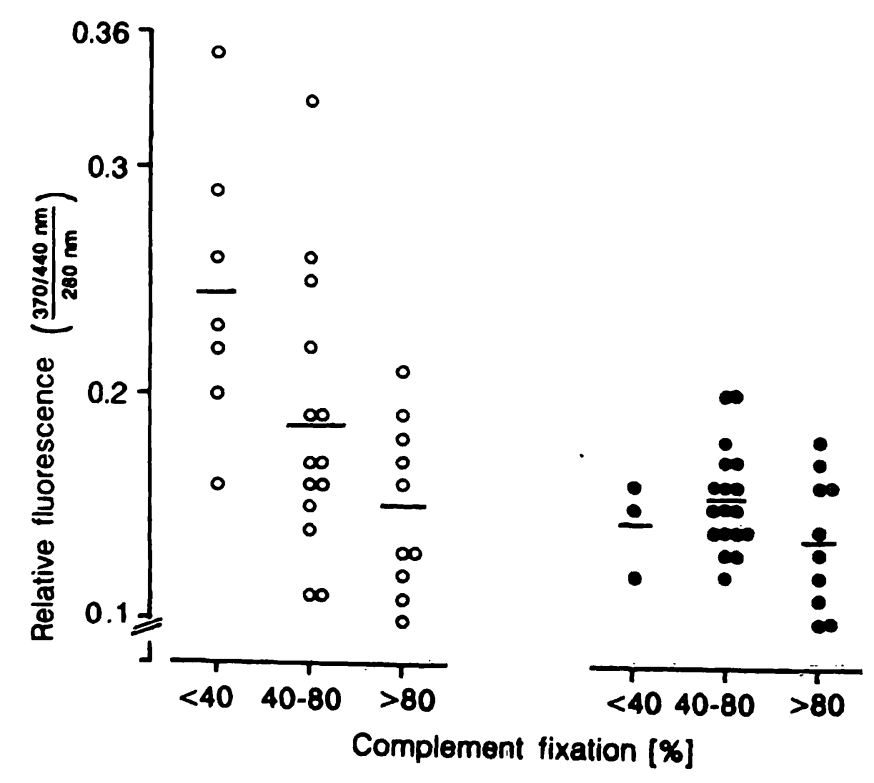

Fig. 9 Relationship between IgG-linked fluorescence and com- 。 plement fixing activity of immunoglobulin $G$ from normal $(\bullet)$ and diabetic $(0)$ subjects.

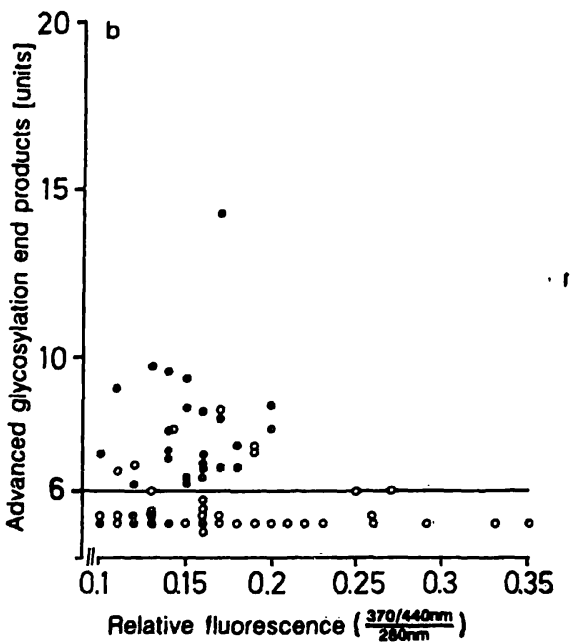

ative fluorescence (b), respectively, in normal controls (甲) and diabetic patients $(0)$.

$(n=76(a)$ and $62(b))$.

$80 \%$ and $>80 \%$ were associated with relative fluorescence values of $0.244 \pm 0.062(n=7), 0.186 \pm 0.061$ $(n=14)$ and $0.15 \pm 0.037(n=10)$, respectively. The difference between each group of diabetics is statistically significant $(p<0.05)$, whereas in normal controls no difference was discernible.

\section{Discussion}

Until recently, advanced glycosylation end products were estimated by indirect, non-specific assays such as measurement of the decrease in solubility (15), of resistance to heat denaturation (16), of absorbance at $350 \mathrm{~nm}$ and of fluorescence at $440 \mathrm{~nm}$ upon excitation at 370 nm $(7,8)$. Furthermore, 2-(2-furoyl)-4(5)-(2-furanyl)1H-imidazole $(17,18)$, 5-hydroxy-methyl-1-alkylpyrrole-2-carbaldehyde (pyrraline) (19), imidazo[4,5-b]pyridinium (pentosidine) (20) and 3-deoxyfructose and 3deoxyglucosone (21) were claimed to represent advanced glycosylation end products formed in vivo and to be present in human serum proteins and tissues. However, detection of single possible advanced glycosylation end products substances in vivo is difficult and cumbersome, since a large number of different browning products is known (22). Nakayama et al. (9) introduced an antibody for immunological determination of advanced glycosylation end products. An antibody of comparable specificity was prepared in our laboratory and used in the present study. This antibody recognizes epitopes which are formed in a time-dependent fashion during incubation of proteins and amino acids with glucose in vitro. These immunologically reactive structures display fluorescence and browning and are not reducible by $\mathrm{NaBH}_{4}$, suggesting the formation of a common advanced glycosylation end products structure(s) by incu- 
bation of proteins or amino acids with glucose, whose nature, however, is not yet known. In this connection it is noteworthy that neither 2-(2-furoyl)-4(5)-(2-furanyl)$1 \mathrm{H}$-imidazole nor pyrraline or pentosidine react with an antibody against advanced glycosylation end products proteins $(9,12,13)$.

From the results of the measurement of IgG-linked fluorescence, it was expected that the subsequently measured levels of immunologically reactive material in IgG preparations would lie well within the range of the calibration curve employed. However, immunoreactivity in $\mathrm{IgG}$, as well as in albumin, was low or undetectable, being higher in normals than in diabetic subjects. This suggests that serum proteins, like IgG or albumin, contain little if any browning products. Possibly, advanced glycosylation end products cannot be formed in considerable amounts because of the short halflife of the serum proteins, or because advanced glycosylation end products serum proteins are rapidly cleared from the circulation by the advanced glycosylation end products receptor (23). Further, the possibility exists that the epitope(s) formed in vitro do not occur in vivo.

It seems reasonable to assume that the marked increase in fluorescence of IgG from diabetics is due to mechanisms other than glycation and browning. Fluorescence can result from the reaction between lipid peroxidation products and proteins (24) and from the oxidation of amino acids by free radicals $(25,26)$. It is known that lipid peroxide levels are increased in diabetics $(27,28)$. Furthermore, it has been demonstrated that early glycation products, Schiff bases and Amadori products, can generate free radicals $(29-31)$. In addition, as shown by Wolff, Hunt and coworkers (32-34), glucose itself can produce free radicals via auto=oxidation. From these re- ports one can conclude that an increase in free radicalmediated oxidation of proteins might occur in hyperglycaemic diabetics.

With respect to the biological activity of IgG from diabetics, to our knowledge we have shown for the first time that certain functional properties of the $\mathrm{Fc}$ region of $\mathrm{IgG}$ from diabetics are impaired, i. e. there is a decrease in binding of protein $\mathrm{A}$ and fixation of complement to the Fc fragment, which probably contributes to the increased susceptibility to infections, known to occur in poorly controlled diabetics (35). The reasons for the changes in the functional properties are unknown. Interaction with protein $\mathrm{A}$ and fixation of complement depend on the integrity of the region 230 to 270 of the heavy chains (36), allowing structural changes of the Fc fragment as a prerequisite for complement binding. One might speculate that oxidation of amino acids in the $\mathrm{Fc}$ region by free radical mechanisms is responsible for damage of the complement binding site, leading to an alteration of biological activity.

The possibility that oxidative mechanisms rather than glycation or browning reaction might be responsible for the impaired $\mathrm{Fc}$ fragment function is supported by the fact that the changes in functional properties are not correlated with the degree of glycation of IgG, absorbance at $350 \mathrm{~nm}$, or immunoreactivity, whereas an inverse relationship was found between IgG-linked fluorescence and complement fixing activity.

\section{Acknowledgement}

We thank Dr. H. U. Janka for allowing us to study his patients.

This work was supported by the Deutsche Forschungsgemeinschaft, Bad Godesberg, Germany.

\section{References}

1. Wieland, O. H. (1983) Protein modification by nonenzymatic glucosylation: Possible role in the development of diabetic complications. Mol. Cell Endocrinol. 29, 125-131.

2. Ruderman, N. B., Williamson, J. R. \& Brownlee, M. (1992) Glucose and diabetic vascular disease. FASEB J. 6, 29052914.

3. Dolhofer-Bliesener, R. \& Gerbitz, K. D. (1990) Effect of nonenzymatic glycation on the structure of immunoglobulin $\mathrm{G}$. Biol. Chem. Hoppe=Seyler 371, 693-697.

4. Dolhofer, R., Siess, E. A. \& Wieland, O. H. (1985) Nonenzymatic glycation of immunoglobulins leads to an impairment of immunoreactivity. Biol. Chem. Hoppe-Seyler 366, 361-366.

5. Dolhofer-Bliesener, R. \& Gerbitz, K. D. (1990) Impairment by glycation of immunoglobulin G Fc fragment function. Scand. J. Clin. Lab. Invest. 50, 739-746.

6. Mallia, A. K., Hermanson, G. T., Krohn, R. I., Fujimoto, E. K. \& Smith, P. K. (1981) Preparation and use of a boronic acid affinity support for separation and quantitation of glycosylated hemoglobins. Anal. Lett. 14, 649-661.

7. Monnier, V. M. \& Cerami, A. (1981) Nonenzymatic browning in vivo: Possible process for aging of long-lived proteins. Science 211, 491-493.

8. Monnier, V. M., Kohn, R. R. \& Cerami, A. (1984) Accelerated age-related browning of human collagen in diabetes mellitus. Proc. Natl. Acad. Sci. USA 8I, 583-587.

9. Nakayama, H., Taneda, S., Kuwajima, S., Aoki, S., Kuroda, Y., Misawa, K. \& Nakagawa, S. (1989) Production and characterization of antibodies to advanced glycation products on proteins. Biochem. Biophys. Res. Commun. 162, 740-745.

10. Nakayama, H., Taneda, S., Mitsuhashi, T., Kuwajima, S., Aoki, S., Kuroda, Y., Misawa, K. Yanagisawa, K. \& Nakagawa, S. (1991) Characterization of antibodies to advanced glycosylation end products on protein. J. Immunol. Methods 140, $119-125$.

11. Sachs, L. (1974) Angewandte Statistik, Springer Verlag, Berlin.

12. Horiuchi, S., Araki, N. \& Morino, Y. (1991) Immunochemical approach to characterize advanced glycation end products of the Maillard reaction. J. Biol. Chem. 266, 7329-7332. 
13. Makita, Z., Vlassara, H., Cerami, A. \& Bucala, R. (1992) Immunochemical detection of advanced glycosylation end products in vivo. J. Biol. Chem. 267, 5133-5138.

14. Eble, A. S., Thorpe, S. R. \& Baynes, J. W. (1983) Nonenzymatic glucosylation and glucose-dependent cross-linking of protein. J. Biol. Chem. 258, 9406-9412.

15. Schnider, S. L. \& Kohn, R. R. (1981) Effects of age and diabetes mellitus on the solubility and nonenzymatic glycosylation of human skin collagen. J. Clin. Invest. 67, 1630-1635.

16. Monnier, V. M., Sell, D. R., Abdul-Karim F. \& Emancipator, S. (1988) Collagen browing and cross-linking are increased in chronic experimental hyperglycemia. Relevance to diabetes and aging. Diabetes 37, 867-872.

17. Pongor, S., Ulrich, P. C., Bencsath, F. A. \& Cerami, A. (1984) Aging of proteins: Isolation and identification of a fluorescent chromophore from the reaction of polypeptides with glucose. Proc. Natl. Acad. Sci. USA 81, 2684-2688.

18. Chang, J. C. F., Ulrich, P. C., Bucala, R. \& Cerami, A. (1985) Detection of an advanced glycosylation product bound to protein in situ. J. Biol. Chem. 260, 7970-7974.

19. Hayase, F., Nagaraj, R. H., Miyata, S., Njoroge, F. G. \& Monnier, V. M. (1989) Aging of proteins: Immunological detection of a glucose-derived pyrrole formed during Maillard reaction in vivo. J. Biol. Chem. 263, 3758-3764.

20. Sell, D. R. \& Monnier, V. M. (1989) Structure elucidation of a senescence cross-link from human extracellular matrix. J. Biol. Chem. 264, 21597-21602.

21. Knecht, K. J., Feather, M. S. \& Baynes, J. W. (1992) Detection of 3-deoxyfructose and 3-deoxyglucosone in human urine and plasma: Evidence for intermediate stages of the Maillard reaction in vivo. Arch. Biochem. Biophys. 294, 130-137.

22. Ledl, F. \& Schleicher, E. (1990) Die Maillard-Reaktion in Lebensmitteln und im menschlichen Körper - neue Ergebnisse zu Chemie, Biochemie und Medizin. Angew. Chemie 102, 597-626.

23. Vlassara, H., Brownlee, M. \& Cerami, A. (1985) High-affinity-receptor-mediated uptake and degradation of glucose-modified proteins: A potential mechanism for the removal of senescent macromolecules. Proc. Natl. Acad. Sci. USA 82, 5588-5592.

24. Chio, K. S. \& Tappel, A. L. (1969) Synthesis and characterization of the fluorescent products derived from malondialdehyde and amino acids. Biochemistry 8, 2827-2832.
25. Wickens, D. G., Norden, A. G., Lunec, J. \& Dormandy, T. L. (1983) Fluorescence changes in human gamma-globulin induced by free-radical activity. Biochim. Biophys. Acta 742, 607-616.

26. Le Guen, C. A., Jones, A. F., Barnett, A. H. \& Lunec, J. (1992) Role of reactive oxygen species in the generation of fluorescence by glycation. Ann. Clin. Biochem. 29, 184-189.

27. Sato, Y., Hotta, N., Sakamoto, $N_{s}$, Matsuoka, S., Ohishi, N. \& Yagi, K. (1979) Lipid peroxide level in plasma of diabetic patients. Biochem. Med. 21, 104-107.

28. Nishigaki, J., Hagihara, M. Tsunekawa, H. Maseki, M. \& Yagi, K. (1981) Lipid peroxide levels of serum lipoprotein fractions of diabetic patients. Biochem. Med. 25, 373-378.

29. Azevedo, M., Falcao, J., Raposo, J. \& Manso, C. (1988) Superoxide radical generation by Amadori compounds. Free Rad. Res. Commun. 4, 331-335.

30. Sakurai, T. \& Tsuchiya, S. (1988) Superoxide production from nonenzymatically glycated protein. FEBS Letters $236,406-$ 410.

31. Mullarkey, C. J., Edelstein, D. \& Brownlee, M. (1990) Free radical generation by early glycation products: A mechanism for accelerated atherogenesis in diabetes. Biochem. Biophys. Res. Commun. 173, 932-939.

32. Wolff, S. P. \& Dean, R. T. (1987) Glucose autooxidation and protein modification. Biochem. J. 245, 243-250.

33. Hunt, J. V., Smith, C. C. T. \& Wolff, S. P. (1990) Autooxydative glycosylation and possible involvement of peroxides and free radicals in LDL modification by glucose. Diabetes 39 , 1420-1424.

34. Wolff, S. P., Jiang, Z. Y. \& Hunt, J. V. (1991) Protein glycation and oxidative stress in diabetes mellitus and aging. Free Radic. Biol. Med. 10, 339-352.

35. Rayfield, E. J., Ault, M. J., Keusch, G. T., Brothers, M. J., Nechemias, C. \& Smith, H. (1982) Infection and diabetes: The case for glucose control. Am. J. Med. 72, 439-450.

36. Stanworth, D. R. \& Turner, M. W. (1978) Immunochemical analysis of immunoglobulins and their sub-units. In: Handbook of Experimental Immunology, Vol. 1 (Weir, D. M., ed.) pp. 6.70-6.71, Blackwell Scientific Publications, Oxford.

Dr. Roswitha Dolhofer-Bliesener Städtisches Krankenhaus München-Schwabing Institut für Klinische Chemie

Kölner Platz 1

D-80804 München

Germany 